\title{
Facial nerve preservation after vestibular schwannoma Gamma Knife radiosurgery
}

\author{
Isaac Yang $\cdot$ Michael E. Sughrue $\cdot$ Seunggu J. Han $\cdot$ \\ Shanna Fang $\cdot$ Derick Aranda $\cdot$ Steven W. Cheung $\cdot$ \\ Lawrence H. Pitts · Andrew T. Parsa
}

Received: 10 December 2008/ Accepted: 23 February 2009

(C) The Author(s) 2009. This article is published with open access at Springerlink.com

\begin{abstract}
Objective Facial nerve preservation is a critical measure of clinical outcome after vestibular schwannoma treatment. Gamma Knife radiosurgery has evolved into a practical treatment modality for vestibular schwannoma patients, with several reported series from a variety of centers. In this study, we report the results of an objective analysis of reported facial nerve outcomes after the treatment of vestibular schwannomas with Gamma Knife radiosurgery. Materials and methods A Boolean Pub Med search of the English language literature revealed a total of 23 published studies reporting assessable and quantifiable outcome data regarding facial nerve function in 2,204 patients who were treated with Gamma Knife radiosurgery for vestibular schwannoma. Inclusion criteria for articles were: (1) Facial nerve preservation rates were reported specifically for vestibular schwannoma, (2) Facial nerve functional outcome was reported using the House-Brackmann classification (HBC) for facial nerve function, (3) Tumor size was documented, and (4) Gamma Knife radiosurgery was the only radiosurgical modality used in the report. The data were then aggregated and analyzed based on radiation doses delivered, tumor volume, and patient age. Results An overall facial nerve preservation rate of $96.2 \%$ was found after Gamma Knife radiosurgery for vestibular schwannoma in our
\end{abstract}

I. Yang - M. E. Sughrue - S. J. Han - S. Fang - D. Aranda ·

L. H. Pitts - A. T. Parsa ( $\square)$

Department of Neurological Surgery, University of California at

San Francisco, 505 Parnassus Ave, San Francisco, CA 94143,

USA

e-mail: ParsaA@Neurosurg.UCSF.Edu

\section{S. W. Cheung}

Department of Otolaryngology-Head and Neck Surgery,

University of California at San Francisco, San Francisco, CA, USA analysis. Patients receiving less than or equal to $13 \mathrm{~Gy}$ of radiation at the marginal dose had a better facial nerve preservation rate than those who received higher doses ( $\leq 13 \mathrm{~Gy}=98.5 \% \quad$ vs. $>13 \mathrm{~Gy}=94.7 \%, \quad P<0.0001)$. Patients with a tumor volume less than or equal to $1.5 \mathrm{~cm}^{3}$ also had a greater facial nerve preservation rate than patients with tumors greater than $1.5 \mathrm{~cm}^{3} \quad\left(\leq 1.5 \mathrm{~cm}^{3} 99.5 \%\right.$ vs. $\left.>1.5 \mathrm{~cm}^{3} 95.5 \%, P<0.0001\right)$. Superior facial nerve preservation was also noted in patients younger than or equal to 60 years of age $(96.8$ vs. $89.4 \%, P<0.0001)$. The average reported follow up duration in this systematic review was $54.1 \pm 31.3$ months. Conclusion Our analysis of case series data aggregated from multiple centers suggests that a facial nerve preservation rate of $96.2 \%$ can be expected after Gamma knife radiosurgery for vestibular schwannoma. Younger patients with smaller tumors less than $1.5 \mathrm{~cm}^{3}$ and treated with lower doses of radiation less than 13 Gy will likely have better facial nerve preservation rates after Gamma Knife radiosurgery for vestibular schwannoma.

Keywords Stereotactic radiosurgery .

Vestibular schwannoma - Facial nerve preservation .

Gamma knife · Acoustic neuroma

\section{Introduction}

Gamma Knife radiosurgery (GKRS) has evolved into a practical alternative treatment to open microsurgical resection of vestibular schwannoma (VS) [1-30]. GKRS as a treatment modality for VS typically does not require inpatient hospitalization, however acute and chronic complications can occur [31-33]. In particular, radiation toxicity of neuro-anatomic structures adjacent to the tumor may develop and manifest as impaired function of the 
facial nerve, hearing loss, or loss of equilibrium and balance. [14, 16, 17, 23, 27, 30, 34-41]. Hydrocephalus, cerebral edema, and other cranial neuropathies have also been documented after GKRS, and in some reported cases required shunting as a treatment for hydrocephalus [4, 23, 37, 42-49].

Despite the available data on facial nerve outcome in VS patients treated with GKRS, there is no consensus as to what reported clinical parameters relate to facial nerve function. Most reported studies to date have been small to modest in size, frequently from a single institution, and lacking the statistical power and freedom from potential practitioner bias to draw concrete conclusions. Our review of the literature revealed widely varying results with reported facial nerve preservation between 55 and $100 \%$ after GKRS for VS (Table 1). Due to these factors and the multitude of methods to assess facial nerve preservation in the reported literature, facial nerve preservation after GKRS has not yet been fully characterized.

Several potential factors affecting facial nerve preservation after GKRS have been suggested, including the dose of radiation delivered, tumor volume, and patient age. In this study, we performed an extensive review of the English Language literature to objectively analyze and methodically evaluate facial nerve outcomes of patients with VS treated with GKRS. The primary aims were to provide an objective summary of the published literature on facial nerve preservation and to evaluate specific prognostic factors that may influence facial nerve preservation after GKRS for VS.

\section{Methodology}

\section{Article selection}

Articles were identified via Boolean PubMed searches using key words "Gamma knife," "radiosurgery," "acoustic neuroma," "facial nerve," "vestibular schwannoma," and "facial nerve preservation," alone and in combination. This query identified 23 papers describing over 2,204 patients from which all quantifiable and assessable data regarding patients treated with radiosurgery were analyzed. Articles published up to and including the year 2007 were included in this analysis. Inclusion criteria for articles were: (1) Facial nerve preservation rates were reported specifically for VS before and after GKRS, (2) Facial nerve outcome was reported using the House-Brackmann classification (HBC) for facial nerve function [5, 50-54], (3) Tumor size was documented, and (4) GKRS was the only radiation modality used to treat the tumor. The data were then aggregated and analyzed based on radiosurgery dose delivered, size of the tumor, and patient age.

\section{Data extraction}

Data from individual and aggregated cases were extracted from each paper. Cases with pre-operative facial dysfunction (HBC 3 or higher) were excluded. All recent cases of open microsurgery and radiotherapy other than GKRS were also excluded. "Facial nerve preservation" was defined as having a grade I or II HBC at the last reported follow-up visit. Overall average for facial preservation, patient age, and radiation dose were weighted accordingly to their sample size, so that larger and smaller series had an appropriate impact on the overall data. Data were analyzed as a whole and stratified into three groups. (1) Radiosurgery marginal dose $\leq 13$ versus $>13$ Gy, (2) Tumor size $\leq 1.5$ versus $>1.5 \mathrm{~cm}^{3}$, and (3) Age $\leq 60$ versus $>60$ years old.

\section{Statistical analysis}

The raw data were tabulated using Microsoft Excel (Microsoft Corp., Seattle, WA). All results were analyzed using a Fisher's exact test or a $t$-test when appropriate for statistical evaluation of the data. For these statistical investigations, tests for significance were two sided, with a (two tailed) $P$-value threshold of 0.05 considered statistically significant. Unless otherwise stated, all continuous values presented were mean \pm standard deviation or standard error of measurement when appropriate.

\section{Results}

Results of comprehensive analysis

A total of 23 articles involving 2,204 patients with 1,908 patients meeting our inclusion criteria, were evaluated [1, 2, 11-13, 16, 17, 26, 41, 43, 44, 55-77] (Table 1). The overall facial nerve functional preservation rate in patients with VS treated with GKRS reported in the included studies was $96.2 \%$. The mean of the reported average age of the patients in this analysis was 55.3 years $( \pm 10.8$; SEM \pm 2.3$)$ with an average of reported length of follow up duration of 54.1 months ( \pm 31.4 months). Median length of follow up time in this analysis was 43.0 months. In this systematic analysis, the average of the published radiation doses used to treat these patients was $13.1 \pm 2 \mathrm{~Gy}(\mathrm{SEM} \pm 0.4)$.

The effect of radiation dose on facial nerve preservation

A total of 1,038 reported patients were treated using an average marginal dose of $\leq 13 \mathrm{~Gy}$, and 801 patients treated with an average marginal dose of $>13$ Gy. In this comparison, the group treated with lower dose radiosurgery (less than or equal to $13 \mathrm{~Gy}$ ) had superior facial nerve preservation 
Table 1 Data summary from papers listed by Pub Med ID and institution

\begin{tabular}{|c|c|c|c|c|c|c|c|c|c|}
\hline PubMed ID & & $\begin{array}{l}\text { Total } \\
\text { sample }\end{array}$ & $\begin{array}{l}\mathrm{CN} \text { VII } \\
\text { intact }\end{array}$ & $\begin{array}{l}\text { Avg } \\
\text { age }\end{array}$ & $\begin{array}{l}\text { Avg dose } \\
\text { (Gy) }\end{array}$ & $\begin{array}{l}\text { Avg } \\
\text { tumor } \\
\text { volume } \\
\left(\mathrm{cm}^{3}\right)\end{array}$ & $\begin{array}{l}\text { Tumor ctrl } \\
\text { rate }(\%)\end{array}$ & $\begin{array}{l}\text { Avg } \\
\text { follow } \\
\text { up (mo.) }\end{array}$ & $\begin{array}{l}\mathrm{CN} \text { VII } \\
\text { preservation } \\
(\%)\end{array}$ \\
\hline 17379451 & University of Pittsburgh & 216 & 215 & 56.5 & 13.0 & 1.300 & 98.30 & 68.4 & 100.0 \\
\hline 16741754 & Ludwig Maximilians University & 123 & 121 & 59 & 13.0 & 1.600 & 96.70 & 98.4 & 100.0 \\
\hline 16094154 & Komaki City Hospital & 317 & 291 & 54 & 13.2 & 5.600 & 92.00 & 93.6 & 96.4 \\
\hline 15854240 & $\begin{array}{l}\text { Haukeland University Hospital, } \\
\text { Norway }\end{array}$ & 103 & 102 & 59.7 & 12.2 & & 89.20 & 70.8 & 94.8 \\
\hline 15662791 & Inst of Neural Org, Japan & 18 & 9 & - & - & 15.200 & 93.33 & 72.0 & 100.0 \\
\hline 15662787 & $\begin{array}{c}\text { Taipei Veterans Gen Hosp and } \\
\text { Natl Yang Ming University }\end{array}$ & 195 & 135 & 51 & 13.0 & 4.100 & 95.00 & 36.0 & 100.0 \\
\hline 15354007 & Medical College of Wisconsin & 29 & 25 & - & 13.5 & & 96.55 & - & 100.0 \\
\hline 15337560 & University of Pittsburgh & 313 & 313 & 56 & 13.0 & 1.100 & 98.60 & 24.0 & 100.0 \\
\hline 14617712 & Royal Hallamshire Hospital, UK & 232 & 179 & 56 & 14.6 & 3.350 & 92.00 & 35.0 & 99.1 \\
\hline 14609174 & Gunma Univ Sch of Med, Japan & 1 & 1 & 63 & 12.0 & 0.520 & 0.00 & 27.0 & 0.0 \\
\hline 14571654 & $\begin{array}{l}\text { Hospital Academique Erasme, } \\
\text { Belgium }\end{array}$ & 48 & 42 & 54.8 & 12.3 & 1.440 & 97.92 & 12.0 & 97.9 \\
\hline 14519213 & University of Pittsburgh & 157 & 124 & 60 & 16.7 & - & 96.90 & 109.2 & 95.0 \\
\hline 12520350 & Addenbrooke's Hospital, England & 5 & 5 & 29 & - & - & 0.00 & - & 80.0 \\
\hline 12459364 & $\begin{array}{l}\text { Baylor memorial Hermann } \\
\text { Hospital }\end{array}$ & 72 & 58 & 61.6 & 14.5 & & 91.00 & 48.0 & 97.4 \\
\hline 12379008 & $\begin{array}{l}\text { Karl-Franzens University, Graz, } \\
\text { Austria }\end{array}$ & 60 & 52 & 58 & 13.0 & 3.400 & 96.00 & 76.0 & 85.0 \\
\hline 11483338 & Thomas Jefferson Univ Hosp, PA & 69 & 57 & 61 & 12.0 & 2.920 & 98.00 & 119.0 & 98.0 \\
\hline 11143268 & University of Tokyo & 1 & 1 & 25 & 14.0 & 0.180 & 100.00 & 60.0 & 100.0 \\
\hline 10821551 & Northwestern Hospital & 9 & 9 & 39 & 19.6 & & 74.00 & - & 55.6 \\
\hline 10030254 & $\begin{array}{l}\text { Mayo Clinic and Mayo Foundation } \\
\text { [reduced protocol] }\end{array}$ & 40 & 33 & 65 & 16.0 & 3.700 & 97.44 & 27.6 & 92.0 \\
\hline 10030254 & $\begin{array}{l}\text { Mayo Clinic and Mayo Foundation } \\
\text { [standard protocol] }\end{array}$ & 42 & 35 & 63 & - & 3.000 & 97.44 & 27.6 & 62.0 \\
\hline 9833820 & $\begin{array}{l}\text { Mayo Clinic/University of } \\
\text { Pittsburgh }\end{array}$ & 76 & 35 & 58 & 15.0 & 2.800 & 94.00 & 43.0 & 83.0 \\
\hline 9392535 & University of Tokyo & 46 & 46 & 54 & 16.8 & - & 96.00 & 39.0 & 80.0 \\
\hline 8588625 & $\begin{array}{l}\text { House Ear Clinic and House Ear } \\
\text { Institute }\end{array}$ & 1 & 1 & 39 & - & - & 0.00 & 24.0 & 100.0 \\
\hline 7826279 & University of Pittsburgh & 31 & 19 & 55 & - & 0.600 & 90.00 & 26.0 & 95.0 \\
\hline Totals and Avg & & 2,204 & 1,908 & 55.3 & 13.1 & 3.2 & 82.5 & 54.1 & 96.2 \\
\hline
\end{tabular}

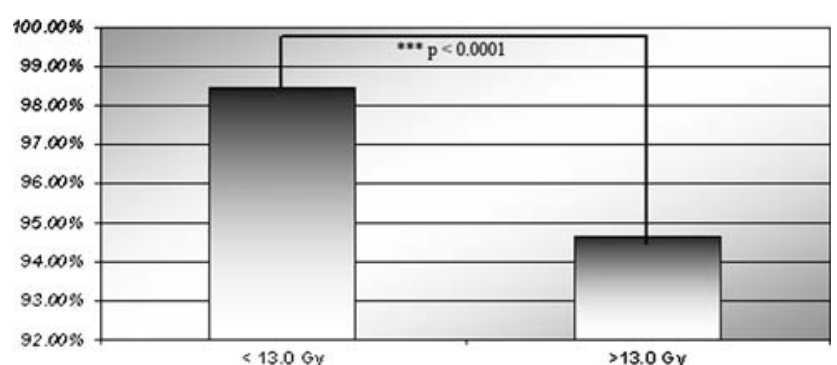

Fig. 1 Facial nerve preservation analyzed by radiation dose of radiosurgery $(P$ value indicated) rates $[\leq 13 \mathrm{~Gy}=98.5 \%$ vs. $>13 \mathrm{~Gy}=94.7 \%, P<0.0001$ (Fig. 1)]. Improved facial nerve preservation with low dose Gamma Knife radiosurgery suggests that radiation dose is a significant prognostic factor for facial nerve preservation with Gamma Knife radiosurgery. Patients with improved facial nerve preservation with low dose GKRS maintained good tumor control rates of $96.7 \%$.

The effect of volume on facial nerve preservation

A total of 591 reported patients in our analysis had an average tumor volume of $1.5 \mathrm{~cm}^{3}$ or less, and 947 patients 


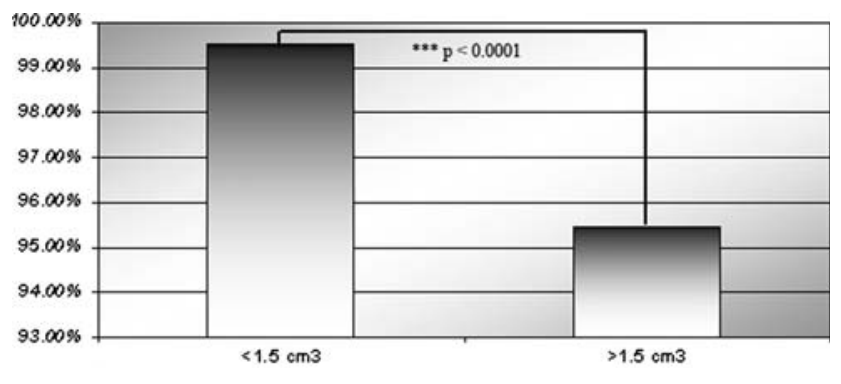

Fig. 2 Facial nerve preservation analyzed by tumor volume stratified by tumors larger and smaller then $1.5 \mathrm{~cm}^{3}$ ( $P$ value indicated)

had an average tumor volume of $>1.5 \mathrm{~cm}^{3}$. The patients with the smaller tumors (measuring $1.5 \mathrm{~cm}^{3}$ or less) had superior facial nerve preservation rates than those with larger tumors $\left[\leq 1.5 \mathrm{~cm}^{3} 99.5 \%\right.$ vs. $>1.5 \mathrm{~cm}^{3} 95.5 \%$, $P<0.0001$ (Fig. 2)]. Smaller tumors were significantly associated with better facial nerve preservation after treatment with GKRS. The mean of the reported average radiation dose for smaller tumors was $12.9 \pm 0.8 \mathrm{~Gy}$ which was less than the $13.7 \pm 1.3 \mathrm{~Gy}$ that larger $\left(>1.5 \mathrm{~cm}^{3}\right)$ tumors received on average $(P<0.0001)$.

The effect of age on facial nerve preservation

A total of 1,690 patients were reported to have an average age equal to or younger than 60 years, and 184 patients were reported to be older than 60 years on average at the time of Gamma Knife radiosurgery. Facial nerve preservation was noted to be worse in patients older than 60 years of age $[\leq 60$ years $=96.8 \%$ vs. $>60$ years $=89.4 \%, P<0.0001$

(Fig. 3)]. Younger and older patients had similar tumor sizes $\left(2.31\right.$ vs. $\left.2.54 \mathrm{~cm}^{3}\right)$ indicating that younger patient had improved facial nerve preservation despite tumor size. Furthermore older patients ( $>57$ years old), treated with higher levels of radiation $(>13 \mathrm{~Gy}$ ) had significantly worse facial nerve outcomes than younger patient $(<57$ years old) treated with similarly higher radiation doses of greater than $13 \mathrm{~Gy}$ $(P<0.0010)$. Younger age may be an important prognostic factor for improved facial nerve preservations with GKRS for VS.

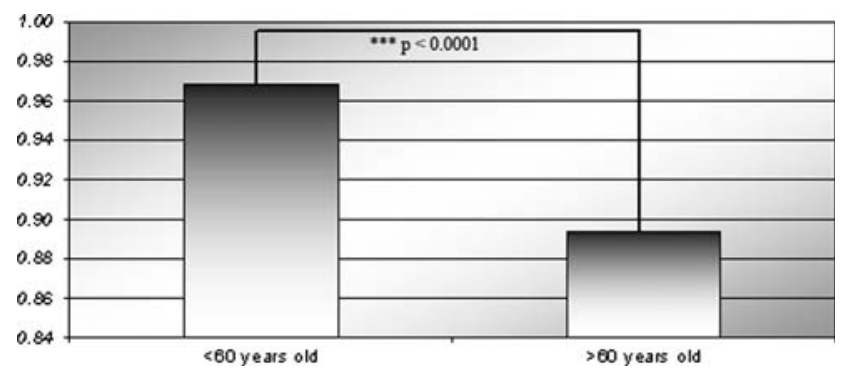

Fig. 3 Facial nerve preservation analyzed as a function of age with an age cut off of older or younger than 60 years old $(P$ value indicated)

\section{Discussion}

Facial nerve preservation continues to be a primary concern of patients undergoing Gamma Knife radiosurgery for vestibular schwannomas. Despite the currently available data there have been few efforts to combine this research into accurate estimates of facial nerve preservation with GKRS for VS. In this study we performed a comprehensive analysis of facial nerve functional preservation in a large aggregated population of patients who underwent GKRS for vestibular schwannomas.

Our methodical analysis revealed that patients treated with a marginal dose of less than 13 Gy were more likely to preserve facial nerve function after GKRS treatment than studies that delivered higher doses of radiation. Higher doses of radiation are associated with higher rates of cranial nerve toxicity [67, 78-81]. One possible reason for this is the significant amount of fibrosis within and around the vestibular schwannoma, involving the adjacent cochlear and facial nerves. This finding has been noted in surgical salvage after failed irradiation [82, 83]. Several recent studies have demonstrated that low dose radiosurgery has a favorable efficacy/toxicity ratio as compared to higher doses $[4,23,40$, $44,48,57,61,84]$. In our analysis patients treated with lower dose Gamma Knife radiosurgery ( $<13 \mathrm{~Gy}$ ) had superior facial nerve preservation rates $[<13 \mathrm{~Gy}=98.5 \%$ vs. $>$ $13 \mathrm{~Gy}=94.7 \%, P<0.0001$ (Fig. 1)] with good tumor control rates of $96.7 \%$ at a reported average length of follow up duration of 54.1 months (Median 43.0 months).

In our objective analysis, patients with an average tumor volume of $1.5 \mathrm{~cm}^{3}$ or less had a better facial nerve preservation rate compared to studies with tumors of larger volumes $\left[<1.5 \mathrm{~cm}^{3} 99.5 \%\right.$ vs. $>1.5 \mathrm{~cm}^{3} 95.5 \%, P<$ 0.0001 (Fig. 2)]. Smaller tumors had improved facial preservation rates and lower average radiation doses for smaller tumors $(12.9 \pm 0.8 \mathrm{~Gy}$ vs. $13.7 \pm 1.3 \mathrm{~Gy}, P<$ 0.0001). This data suggests that both smaller tumor size and lower radiosurgery dose are important risk factors for facial nerve preservation with Gamma knife radiosurgery treatment. Although it appears that radiation dose is an important associated factor with facial nerve preservation, our data does not permit the discrimination between size or radiation dose as the more significant parameter for facial nerve preservation as both smaller tumors and lower radiation doses both had improved outcomes. Our data does not clarify this ambiguity about whether size or radiation dose has a more significant impact on facial nerve preservation.

Older patients commonly have medically related comorbidities which can preclude them from open brain surgery. Our analysis indicates that older patients with age $>60$ years had inferior facial nerve preservation rates than younger patients $[<60$ years $=96.8 \%$ vs. $>60$ years $=$ $89.4 \%, P<0.0001$ (Fig. 3)]. Age may be an important 
prognostic factor for facial nerve preservation despite tumor size or radiation dose. Older patients had similar tumor sizes as younger patients $\left(2.31\right.$ vs. $\left.2.54 \mathrm{~cm}^{3}\right)$. Advanced age does appear to be a negative prognostic factor in facial nerve preservation outcomes in patients treated with GKRS for VS. Furthermore older patients ( $>57$ years old), treated with high levels of radiation $(>13 \mathrm{~Gy})$ had significantly worse facial nerve outcomes than younger patient ( $<57$ years old) treated with similarly high radiation doses of greater than $13 \mathrm{~Gy}(P<0.0010)$. Our data suggests that older age may be significantly associated with worse facial nerve preservation independent of radiation dose because older patients did worse with high radiation doses than their younger counterparts who also received high radiation doses (>13 Gy).

The various methods of data presentation reported in the papers for our systematic analysis precluded us from further investigation to stratify other statistically significant data points. Unfortunately actuarial time dependant data was not possible in our retrospective, systematic analysis as this is an inherent limitation in the methodology of our study. Similarly, multi-variable analysis and a logistic regression analysis are also problematic across multiple studies which adhere to differing formats of data presentation.

Prospective studies could further elucidate the actuarial nature of facial nerve preservation over time after GKRS and may also provide further insight into the exact relationship between the prognostic variables we investigated here and facial nerve preservation. Our systematic analysis is the first reported attempt to comprehensively evaluate the overall impact of GKRS for VS on facial nerve function as described in the published literature.

There are some inherent limitations with systematic reviews and analysis [85]. One obvious limitation is that any aggregation of data is only as good as its composite studies. The quality of the data reported in the literature, the effect of failure to detect, or unwillingness to report complications, and other such omissions would inevitably change and skew the result reported in our aggregated analysis. Furthermore, small sample size reports that met our inclusion criteria were also included in our analysis. Although their contribution is small, we mitigated the effect of case reports and small samples by analyzing an aggregated database and by weighting the appropriate contribution of each paper by the number of patients with facial nerve intact before GKRS accordingly. Hence in our analysis, smaller sample sizes and case reports had a proportionate effect on our overall aggregated facial nerve preservation data. However, the large nature of our systematic review minimizes the biases and dilutes the inherent error of any individual study in our comprehensive report and also has the advantage of expansive results from multiple international centers.
In conclusion, we report the results from a large aggregated analysis of facial nerve outcomes in patients with vestibular schwannoma treated specifically with Gamma Knife radiosurgery. Utilizing this systematic data set from the available published literature, minimizes the effect of bias and dilutes the inherent error from individual institutions, increases the statistical power of our analysis, and aggregates expansive results to determine an accurate and overall facial nerve preservation for patients treated with Gamma Knife radiosurgery for vestibular schwannomas. This systematic analysis suggests that radiation dose is an important and critical prognostic factor for facial nerve outcomes in VS patients treated with GKRS. Our data also confirms that patients treated with 13 Gy or less of radiation, with tumors less than $1.5 \mathrm{~cm}^{3}$ in size, and younger patients have improved facial nerve outcomes.

Acknowledgments IY the first author was partially supported by a UCSF Clinical and Translational Scientist Training Research Award in performing this investigation. ATP senior author is partially funded by the Reza and Georgianna Khatib Endowed Chair in Skull Base Tumor Surgery.

Open Access This article is distributed under the terms of the Creative Commons Attribution Noncommercial License which permits any noncommercial use, distribution, and reproduction in any medium, provided the original author(s) and source are credited.

\section{References}

1. Delbrouck C, Hassid S, Massager N, Choufani G, David P, Devriendt D, Levivier M (2003) Preservation of hearing in vestibular schwannomas treated by radiosurgery using Leksell Gamma Knife: preliminary report of a prospective Belgian clinical study. Acta Otorhinolaryngol Belg 57:197-204

2. Karpinos M, Teh BS, Zeck O, Carpenter LS, Phan C, Mai WY, Lu HH, Chiu JK, Butler EB, Gormley WB, Woo SY (2002) Treatment of acoustic neuroma: stereotactic radiosurgery vs. microsurgery. Int J Radiat Oncol Biol Phys 54:1410-1421. doi: 10.1016/S0360-3016(02)03651-9

3. Kaylie DM, McMenomey SO (2003) Microsurgery vs gamma knife radiosurgery for the treatment of vestibular schwannomas. Arch Otolaryngol Head Neck Surg 129:903-906. doi:10.1001/ archotol.129.8.903

4. Kondziolka D, Lunsford LD, McLaughlin MR, Flickinger JC (1998) Long-term outcomes after radiosurgery for acoustic neuromas. N Engl J Med 339:1426-1433. doi:10.1056/NEJM1998 11123392003

5. Flickinger JC, Kondziolka D, Lunsford LD (1998) Clinical applications of stereotactic radiosurgery. Cancer Treat Res 93:283-297

6. Noren G (1998) Long-term complications following gamma knife radiosurgery of vestibular schwannomas. Stereotact Funct Neurosurg 70(Suppl 1):65-73. doi:10.1159/000056408

7. Pellet W, Regis J, Roche PH, Delsanti C (2003) Relative indications for radiosurgery and microsurgery for acoustic schwannoma. Adv Tech Stand Neurosurg 28:227-282; discussion 282-284 
8. Pogodzinski MS, Harner SG, Link MJ (2004) Patient choice in treatment of vestibular schwannoma. Otolaryngol Head Neck Surg 130:611-616. doi:10.1016/j.otohns.2004.02.006

9. Regis J, Delsanti C, Roche P, Soumare O, Dufour H, Porcheron D, Peragut JC, Thomassin JM, Pellet W (2002) Preservation of hearing function in the radiosurgical treatment of unilateral vestibular schwannomas. Preliminary results. Neurochirurgie 48:471-478

10. Regis J, Pellet W, Delsanti C, Dufour H, Roche PH, Thomassin JM, Zanaret M, Peragut JC (2002) Functional outcome after gamma knife surgery or microsurgery for vestibular schwannomas. J Neurosurg 97:1091-1100

11. Unger F, Walch C, Papaefthymiou G, Feichtinger K, Trummer M, Pendl G (2002) Radiosurgery of residual and recurrent vestibular schwannomas. Acta Neurochir (Wien) 144:671-676; discussion 676-677

12. Unger F, Walch C, Schrottner O, Eustacchio S, Sutter B, Pendl G (2002) Cranial nerve preservation after radiosurgery of vestibular schwannomas. Acta Neurochir Suppl (Wien) 84:77-83

13. Unger F, Walch C, Haselsberger K, Papaefthymiou G, Trummer M, Eustacchio S, Pendl G (1999) Radiosurgery of vestibular schwannomas: a minimally invasive alternative to microsurgery. Acta Neurochir (Wien) 141:1281-1285; discussion 1285-1286

14. Friedman WA, Foote KD (2003) Linear accelerator-based radiosurgery for vestibular schwannoma. Neurosurg Focus 14:e2

15. Shoshan Y, Wygoda M, Umansky F (2005) Stereotactic radiosurgery and fractionated stereotactic radiotherapy: background, definitions, applications. Isr Med Assoc J 7:597-599

16. Battista RA, Wiet RJ (2000) Stereotactic radiosurgery for acoustic neuromas: a survey of the American Neurotology Society. Am J Otol 21:371-381. doi:10.1016/S0196-0709(00)80047-2

17. Pollock BE, Lunsford LD, Kondziolka D, Flickinger JC, Bissonette DJ, Kelsey SF, Jannetta PJ (1995) Outcome analysis of acoustic neuroma management: a comparison of microsurgery and stereotactic radiosurgery. Neurosurgery 36:215-224; discussion 224-229

18. Sekhar LN, Gormley WB, Wright DC (1996) The best treatment for vestibular schwannoma (acoustic neuroma): microsurgery or radiosurgery? Am J Otol 17:676-682; discussion 683-689

19. Kamerer DB, Lunsford LD, Moller M (1988) Gamma knife: an alternative treatment for acoustic neurinomas. Ann Otol Rhinol Laryngol 97:631-635

20. Lunsford LD, Kamerer DB, Flickinger JC (1990) Stereotactic radiosurgery for acoustic neuromas. Arch Otolaryngol Head Neck Surg 116:907-909

21. Wiet RJ, Micco AG, Bauer GP (1996) Complications of the gamma knife. Arch Otolaryngol Head Neck Surg 122:414-416

22. Ramsay HA, Luxford WM (1993) Treatment of acoustic tumours in elderly patients: is surgery warranted? $\mathrm{J}$ Laryngol Otol 107:295-297. doi:10.1017/S0022215100122868

23. Mendenhall WM, Friedman WA, Buatti JM, Bova FJ (1996) Preliminary results of linear accelerator radiosurgery for acoustic schwannomas. J Neurosurg 85:1013-1019

24. Linskey ME (2000) Stereotactic radiosurgery versus stereotactic radiotherapy for patients with vestibular schwannoma: a Leksell Gamma Knife Society 2000 debate. J Neurosurg 93(Suppl 3): 90-95

25. Yamamoto M, Hagiwara S, Ide M, Jimbo M, Hirai T, Nakamura Y (1996) Radiosurgery for acoustic neurinoma with rapid growth and relatively high staining indexes for proliferating cell nuclear antigen and MIB-1. Neurol Med Chir (Tokyo) 36:241-245. doi: 10.2176/nmc.36.241

26. Flickinger JC, Lunsford LD, Linskey ME, Duma CM, Kondziolka D (1993) Gamma knife radiosurgery for acoustic tumors: multivariate analysis of four year results. Radiother Oncol 27:9198. doi:10.1016/0167-8140(93)90127-T
27. Lunsford LD, Linskey ME (1992) Stereotactic radiosurgery in the treatment of patients with acoustic tumors. Otolaryngol Clin N Am 25:471-491

28. Spiegelmann R, Gofman J, Alezra D, Pfeffer R (1999) Radiosurgery for acoustic neurinomas (vestibular schwannomas). Isr Med Assoc J 1:8-13

29. Ottaviani F, Neglia CB, Ventrella L, Giugni E, Motti E (2002) Hearing loss and changes in transient evoked otoacoustic emissions after gamma knife radiosurgery for acoustic neurinomas. Arch Otolaryngol Head Neck Surg 128:1308-1312

30. Ito K, Shin M, Matsuzaki M, Sugasawa K, Sasaki T (2000) Risk factors for neurological complications after acoustic neurinoma radiosurgery: refinement from further experiences. Int J Radiat Oncol Biol Phys 48:75-80. doi:10.1016/S0360-3016(00)00570-8

31. Yang I, Barbaro NM (2007) Advances in the radiosurgical treatment of epilepsy. Epilepsy Curr/Am Epilepsy Soc 7:31-35

32. Chin LS, Lazio BE, Biggins T, Amin P (2000) Acute complications following gamma knife radiosurgery are rare. Surg Neurol 53:498-502; discussion 502

33. de Ipolyi AR, Yang I, Buckley A, Barbaro NM, Cheung SW, Parsa AT (2008) Fluctuating response of a cystic vestibular schwannoma to radiosurgery: case report. Neurosurgery 62: E1164-E1165, E:1165 discussion

34. Doherty JK, Friedman RA (2006) Controversies in building a management algorithm for vestibular schwannomas. Curr Opin Otolaryngol Head Neck Surg 14:305-313. doi:10.1097/01.moo. 0000244186.72645.d4

35. Linskey ME, Lunsford LD, Flickinger JC (1990) Radiosurgery for acoustic neurinomas: early experience. Neurosurgery 26:736744; discussion 744-745

36. Linskey ME, Johnstone PA, O’Leary M, Goetsch S (2003) Radiation exposure of normal temporal bone structures during stereotactically guided gamma knife surgery for vestibular schwannomas. J Neurosurg 98:800-806

37. Smith MC, Ryken TC, Buatti JM (2006) Radiotoxicity after conformal radiation therapy for benign intracranial tumors. Neurosurg Clin N Am 17:169-180. doi:10.1016/j.nec.2006.04.002

38. Mendenhall WM, Friedman WA, Bova FJ (1994) Linear accelerator-based stereotactic radiosurgery for acoustic schwannomas. Int J Radiat Oncol Biol Phys 28:803-810

39. Spiegelmann R, Lidar Z, Gofman J, Alezra D, Hadani M, Pfeffer $\mathrm{R}$ (2001) Linear accelerator radiosurgery for vestibular schwannoma. J Neurosurg 94:7-13

40. Foote KD, Friedman WA, Buatti JM, Meeks SL, Bova FJ, Kubilis PS (2001) Analysis of risk factors associated with radiosurgery for vestibular schwannoma. J Neurosurg 95:440-449

41. Myrseth E, Moller P, Pedersen PH, Vassbotn FS, Wentzel-Larsen T, Lund-Johansen M (2005) Vestibular schwannomas: clinical results and quality of life after microsurgery or gamma knife radiosurgery. Neurosurgery 56: 927-935; discussion 927-935

42. Shin YJ, Lapeyre-Mestre M, Gafsi I, Cognard C, Deguine O, Tremoulet M, Fraysse B (2003) Neurotological complications after radiosurgery versus conservative management in acoustic neuromas: a systematic review-based study. Acta Otolaryngol 123:59-64. doi:10.1081/0036554021000028084

43. Chung WY, Liu KD, Shiau CY, Wu HM, Wang LW, Guo WY, Ho DM, Pan DH (2005) Gamma knife surgery for vestibular schwannoma: 10-year experience of 195 cases. J Neurosurg 102(Suppl):87-96

44. Andrews DW, Suarez O, Goldman HW, Downes MB, Bednarz G, Corn BW, Werner-Wasik M, Rosenstock J, Curran WJ Jr (2001) Stereotactic radiosurgery and fractionated stereotactic radiotherapy for the treatment of acoustic schwannomas: comparative observations of 125 patients treated at one institution. Int J Radiat Oncol Biol Phys 50:1265-1278. doi:10.1016/S0360-3016(01) 01559-0 
45. Meijer OW, Vandertop WP, Baayen JC, Slotman BJ (2003) Singlefraction vs. fractionated linac-based stereotactic radiosurgery for vestibular schwannoma: a single-institution study. Int $\mathbf{J}$ Radiat Oncol Biol Phys 56:1390-1396. doi:10.1016/S0360-3016(03) 00444-9

46. Meijer OW, Wolbers JG, Baayen JC, Slotman BJ (2000) Fractionated stereotactic radiation therapy and single high-dose radiosurgery for acoustic neuroma: early results of a prospective clinical study. Int J Radiat Oncol Biol Phys 46:45-49. doi: 10.1016/S0360-3016(99)00363-6

47. Thomsen J, Tos M, Borgesen SE (1990) Gamma knife: hydrocephalus as a complication of stereotactic radiosurgical treatment of an acoustic neuroma. Am J Otol 11:330-333

48. Kondziolka D, Subach BR, Lunsford LD, Bissonette DJ, Flickinger JC (1998) Outcomes after gamma knife radiosurgery in solitary acoustic tumors and neurofibromatosis type 2. Neurosurg Focus 5:e2. doi:10.3171/foc.1998.5.3.5

49. Hudgins WR (1994) Patients' attitude about outcomes and the role of gamma knife radiosurgery in the treatment of vestibular schwannomas. Neurosurgery 34:459-463; discussion 463-465

50. House JW, Brackmann DE (1985) Facial nerve grading system. Otolaryngol Head Neck Surg 93:146-147

51. Silverstein H, Willcox TO Jr, Rosenberg SI, Seidman MD (1994) Prediction of facial nerve function following acoustic neuroma resection using intraoperative facial nerve stimulation. Laryngoscope 104:539-544. doi:10.1288/00005537-199412000-00002

52. Ross BG, Fradet G, Nedzelski JM (1996) Development of a sensitive clinical facial grading system. Otolaryngol Head Neck Surg 114:380-386. doi:10.1016/S0194-5998(96)70206-1

53. Neely JG, Joaquin AH, Kohn LA, Cheung JY (1996) Quantitative assessment of the variation within grades of facial paralysis. Laryngoscope 106:438-442. doi:10.1097/00005537-19960400000009

54. Rickenmann J, Jaquenod C, Cerenko D, Fisch U (1997) Comparative value of facial nerve grading systems. Otolaryngol Head Neck Surg 117:322-325. doi:10.1016/S0194-5998(97)70120-7

55. Chopra R, Kondziolka D, Niranjan A, Lunsford LD, Flickinger JC (2007) Long-term follow-up of acoustic schwannoma radiosurgery with marginal tumor doses of 12 to 13 Gy. Int J Radiat Oncol Biol Phys 68:845-851. doi:10.1016/j.ijrobp.2007.01.001

56. Hempel JM, Hempel E, Wowra B, Schichor C, Muacevic A, Riederer A (2006) Functional outcome after gamma knife treatment in vestibular schwannoma. Eur Arch Otorhinolaryngol 263:714-718. doi:10.1007/s00405-006-0054-6

57. Hasegawa T, Kida Y, Kobayashi T, Yoshimoto M, Mori Y, Yoshida J (2005) Long-term outcomes in patients with vestibular schwannomas treated using gamma knife surgery: 10-year follow up. J Neurosurg 102:10-16

58. Lunsford LD, Niranjan A, Flickinger JC, Maitz A, Kondziolka D (2005) Radiosurgery of vestibular schwannomas: summary of experience in 829 cases. J Neurosurg 102(Suppl):195-199

59. Inoue HK (2005) Low-dose radiosurgery for large vestibular schwannomas: long-term results of functional preservation. J Neurosurg 102(Suppl):111-113

60. Wackym PA, Runge-Samuelson CL, Poetker DM, Michel MA, Alkaf FM, Burg LS, Firszt JB (2004) Gamma knife radiosurgery for acoustic neuromas performed by a neurotologist: early experiences and outcomes. Otol Neurotol 25:752-761. doi: 10.1097/00129492-200409000-00018

61. Flickinger JC, Kondziolka D, Niranjan A, Maitz A, Voynov G, Lunsford LD (2004) Acoustic neuroma radiosurgery with marginal tumor doses of 12 to 13 Gy. Int J Radiat Oncol Biol Phys 60:225-230. doi:10.1016/j.ijrobp.2004.02.019

62. Rowe JG, Radatz MW, Walton L, Soanes T, Rodgers J, Kemeny AA (2003) Clinical experience with gamma knife stereotactic radiosurgery in the management of vestibular schwannomas secondary to type 2 neurofibromatosis. J Neurol Neurosurg Psychiatry 74:1288-1293. doi:10.1136/jnnp.74.9.1288

63. Watanabe T, Saito N, Hirato J, Shimaguchi H, Fujimaki H, Sasaki T (2003) Facial neuropathy due to axonal degeneration and microvasculitis following gamma knife surgery for vestibular schwannoma: a histological analysis. Case report. J Neurosurg 99:916-920

64. Kondziolka D, Nathoo N, Flickinger JC, Niranjan A, Maitz AH, Lunsford LD (2003) Long-term results after radiosurgery for benign intracranial tumors. Neurosurgery 53:815-821; discussion 821-822

65. Moffat DA, Quaranta N, Baguley DM, Hardy DG, Chang P (2003) Management strategies in neurofibromatosis type 2. Eur Arch Otorhinolaryngol 260:12-18

66. Tago M, Terahara A, Nakagawa K, Aoki Y, Ohtomo K, Shin M, Kurita H (2000) Immediate neurological deterioration after gamma knife radiosurgery for acoustic neuroma. Case report. J Neurosurg 93(Suppl 3):78-81

67. Niranjan A, Lunsford LD, Flickinger JC, Maitz A, Kondziolka D (1999) Dose reduction improves hearing preservation rates after intracanalicular acoustic tumor radiosurgery. Neurosurgery 45:753-762; discussion 762-765

68. Subach BR, Kondziolka D, Lunsford LD, Bissonette DJ, Flickinger JC, Maitz AH (1999) Stereotactic radiosurgery in the management of acoustic neuromas associated with neurofibromatosis type 2. J Neurosurg 90:815-822

69. Miller RC, Foote RL, Coffey RJ, Sargent DJ, Gorman DA, Schomberg PJ, Kline RW (1999) Decrease in cranial nerve complications after radiosurgery for acoustic neuromas: a prospective study of dose and volume. Int J Radiat Oncol Biol Phys 43:305-311. doi:10.1016/S0360-3016(98)00397-6

70. Pollock BE, Lunsford LD, Flickinger JC, Clyde BL, Kondziolka D (1998) Vestibular schwannoma management. Part I. Failed microsurgery and the role of delayed stereotactic radiosurgery. $\mathrm{J}$ Neurosurg 89:944-948

71. Ito K, Kurita H, Sugasawa K, Mizuno M, Sasaki T (1997) Analyses of neuro-otological complications after radiosurgery for acoustic neurinomas. Int J Radiat Oncol Biol Phys 39:983-988. doi:10.1016/S0360-3016(97)00507-5

72. Flickinger JC, Kondziolka D, Lunsford LD (1996) Dose and diameter relationships for facial, trigeminal, and acoustic neuropathies following acoustic neuroma radiosurgery. Radiother Oncol 41:215-219. doi:10.1016/S0167-8140(96)01831-2

73. Flickinger JC, Kondziolka D, Pollock BE, Lunsford LD (1996) Evolution in technique for vestibular schwannoma radiosurgery and effect on outcome. Int J Radiat Oncol Biol Phys 36:275-280. doi:10.1016/S0360-3016(96)00335-5

74. Slattery WH III, Brackmann DE (1995) Results of surgery following stereotactic irradiation for acoustic neuromas. Am J Otol 16:315-319; discussion 319-321

75. Ogunrinde OK, Lunsford LD, Flickinger JC, Kondziolka DS (1995) Cranial nerve preservation after stereotactic radiosurgery for small acoustic tumors. Arch Neurol 52:73-79

76. Ogunrinde OK, Lunsford DL, Kondziolka DS, Bissonette DJ, Flickinger JC (1995) Cranial nerve preservation after stereotactic radiosurgery of intracanalicular acoustic tumors. Stereotact Funct Neurosurg 64(Suppl 1):87-97

77. Linskey ME, Lunsford LD, Flickinger JC (1992) Tumor control after stereotactic radiosurgery in neurofibromatosis patients with bilateral acoustic tumors. Neurosurgery 31:838-839; discussion 838-839

78. Hirato $\mathrm{M}$, Inoue $\mathrm{H}$, Zama A, Ohye $\mathrm{C}$, Shibazaki $\mathrm{T}$, Andou $\mathrm{Y}$ (1996) Gamma knife radiosurgery for acoustic schwannoma: effects of low radiation dose and functional prognosis. Stereotact Funct Neurosurg 66(Suppl 1):134-141. doi:10.1159/00009 9803 
79. Niranjan A, Lunsford LD, Flickinger JC, Maitz A, Kondziolka D (1999) Can hearing improve after acoustic tumor radiosurgery? Neurosurg Clin N Am 10:305-315

80. Petit JH, Hudes RS, Chen TT, Eisenberg HM, Simard JM, Chin LS (2001) Reduced-dose radiosurgery for vestibular schwannomas. Neurosurgery 49:1299-1306; discussion 1306-1307

81. Rutten I, Baumert BG, Seidel L, Kotolenko S, Collignon J, Kaschten B, Albert A, Martin D, Deneufbourg JM, Demanez JP, Stevenaert A (2007) Long-term follow-up reveals low toxicity of radiosurgery for vestibular schwannoma. Radiother Oncol 82:8389. doi:10.1016/j.radonc.2006.11.019

82. Friedman RA, Brackmann DE, Hitselberger WE, Schwartz MS, Iqbal Z, Berliner KI (2005) Surgical salvage after failed irradiation for vestibular schwannoma. Laryngoscope 115:18271832. doi: $10.1097 / 01 . m l g .0000175063 .76945 .75$

83. Limb CJ, Long DM, Niparko JK (2005) Acoustic neuromas after failed radiation therapy: challenges of surgical salvage. Laryngoscope 115:93-98

84. Hasegawa T, Fujitani S, Katsumata S, Kida Y, Yoshimoto M, Koike J (2005) Stereotactic radiosurgery for vestibular schwannomas: analysis of 317 patients followed more than 5 years. Neurosurgery 57:257-265; discussion 257-265

85. Barker FGII, Carter BS (2005) Synthesizing medical evidence: systematic reviews and metaanalyses. Neurosurg Focus 19:E5. doi:10.3171/foc.2005.19.4.6 